\title{
Construction and Standardization of Dementia Arabic Scale
}

This article was published in the following Dove Press journal:

Neuropsychiatric Disease and Treatment

\author{
Wafaa M Farghaly (D) \\ Hamdy N El Tallawy' \\ Heba Mohamed' \\ Sara H El Tallawy ${ }^{2}$ \\ Mohamed A Abdelhamed (D) \\ 'Department of Neuropsychiatry, and \\ Neuroepidemiology Lab, Faculty of \\ Medicine, Assiut University, Assiut, Egypt; \\ ${ }^{2}$ Department of Psychology, Faculty of \\ Arts, Assiut University, Assiut, Egypt
}

Purpose: Validated diagnostic scales for dementia in Arabic are still scarce. The aim of this study is to construct a standardized dementia scale for dementia diagnosis among the Arabicspeaking population.

Patients and Methods: Construction of the Dementia Arabic Scale (DAS) was done, followed by evaluation of content validity. A pilot study was done to ascertain feasibility and language clarity used in the scale. Patients diagnosed to have major neurocognitive disorder according to DSM-V criteria and control group were subjected to DAS, mini-mental state examination (MMSE) and Cognitive Abilities Screening Instrument (CASI). Finally, standardization of the scale and estimation of cutoff point, sensitivity, specificity, positive predictive value and negative predictive value of the newly constructed scale (DAS) were done.

Results: There is significant correlation between DAS and both MMSE and CASI on Pearson's correlation study. The internal consistency of the DAS scale was good, with Cronbach's alpha correlation coefficient of 0.88 . At cut-off $\leq 95$ for literate, and $\leq 68$ for illiterate, the sensitivity of the DAS scale was $100 \%, 87 \%$ for literate and illiterate, respectively, while specificity was $84 \%, 96 \%$ respectively, with an area under the receiver operating characteristic curve of (AUC) 0.96 .

Conclusion: The DAS scale is an acceptable, reliable and valid scale for the diagnosis of dementia in Arabic-speaking countries.

Keywords: dementia, cognitive screening test, standardization, validity

\section{Introduction}

Dementias have tremendous consequences for individuals, their families, and the healthcare system. ${ }^{1}$ It was found that the prevalence of dementia varies worldwide. It is estimated that $5-8 \%$ of the general population aged 60 years and over have dementia. $^{2}$ Previous studies on the prevalence of dementia in Egypt stated that it ranges from $2.01-5.07 \%$. $^{3-6}$ Given these estimates, and the expected increase in the prevalence of dementia over the next years, accurate and early diagnosis of these cases is mandatory for proper health planning and management.

Epidemiological studies on dementia depend mainly on screening and diagnostic scales. An obstacle facing early diagnosis and accurate estimates of dementia among the Arabic-speaking countries is the paucity of screening and diagnostic instruments, that were constructed in Arabic to avoid cultural, educational, and linguistic differences, that can affect the result of the screening tests. ${ }^{7}$

Previous studies have reported that mini-mental state examination (MMSE), ${ }^{8}$ is affected by age, sex, and educational level. ${ }^{9,10}$ However, it is still one of the most widely used screening test for dementia in Arab countries. ${ }^{11,12}$ MMSE may be not
Correspondence: Mohamed A Abdelhamed Department of Neuropsychiatry, and Neuroepidemiology research center, Faculty of medicine, Assiut University, 7th Floor,

Assiut, 71926, Egypt

Tel +00201002629734

Fax +20882333327

Email moh78_abdelhamed@aun.edu.eg
Neuropsychiatric Disease and Treatment 2021:17 721-729

\section{Neuropsychiatric Disease and Treatment 2021:17 721-729}

(c) (1) (5) 2021 Farghaly et al. This work is published and licensed by Dove Medical Press Limited. The full terms of this license are available at https://www.dovepress.com/terms. work you hereby accept the Terms. Non-commercial uses of the work are permitted without any further permission from Dove Medical Press Limited, provided the work is properly attributed. For permission for commercial use of this work, please see paragraphs 4.2 and 5 of our Terms (https://www.dovepress.com/terms.php). 
suitable for the Arabic-speaking populations, where a high proportion of elderly are illiterate, while the test requires arithmetical ability, reading and writing skills.

Although the translation and validation of scales to the Arabic language were done through a few previous studies, ${ }^{13-19}$ there is still a need to construct a dementia Arabic scale that suits the educational and culture background for each population and covers wide areas of cognitive function.

Construction of a standardized Arabic scale that captures cognitive impairment related to dementia could potentially be of great value, considering the widespread use of the Arabic language and the problems that exist with using translated foreign instruments. In addition, as health care facilities improve, more people will reach an age at which dementia becomes an issue, so an Arabic diagnostic instrument will become increasingly relevant. This study was developed to construct a standardized Arabic scale for dementia diagnosis among Arabic-speaking populations.

\section{Patients and Methods}

This study consisted of 240 subjects, recruited from those attending our university hospital outpatients clinic or inpatients ward during the period from 2017-2018, and divided into two groups:

The patient's group includes 120 patients proved to have dementia according to the fifth edition of the Diagnostic and
Statistical Manual of Mental Disorders (DSM-5), ${ }^{20}$ and documented by standard psychometric tests \{obtaining $<23$ for literate patients or $<21$ for illiterate patients on the Arabic version of MMSE), ${ }^{21,22}$ and obtaining $<80$ for literate patients and $<50$ for illiterate patients on the Cognitive Abilities Screening Instrument (CASI). ${ }^{23,24}$ Based on DSM-5, sixty-four patients with neurocognitive disorders (NCD) were categorized as Alzheimer's disease, 50 patients as vascular dementia, 3 as Parkinson's disease dementia and 3 as frontotemporal lobar degeneration.

Patients known to have a psychiatric illness (schizophrenia, mood disorder), severe sensory impairment (blindness, and/or deafness), aphasia or dysphasia, and persons refused to participate in this study were excluded.

The control group includes 120 participants with normal cognitive function as documented by MMSE and CASI. Control subjects were age, sex, and educationally matched healthy subjects recruited from volunteers of patient's relatives and paramedical personnel. The demographic characteristics of the study population are shown in Table 1.

\section{Strategy of the Work}

The First Stage: Construction of the Dementia Arabic Scale (DAS)

All questions in the Dementia Arabic Scale (Appendix1) were suggested by members of the team after meticulous reading of different international standardized scales,

Table I Socio-Demographic Data and Dementia Scale Scores Comparison in Cases vs Controls

\begin{tabular}{|c|c|c|c|}
\hline Variables & Cases $(n=120)$ & Controls $(n=120)$ & P-value \\
\hline \multicolumn{4}{|l|}{ Age/Years } \\
\hline - Mean \pm SD & $68.45 \pm 8.5$ & $66.43 \pm 12.2$ & $=0.139 *$ \\
\hline - Median and range & $68(50-87)$ & $63.5(50-89)$ & \\
\hline \multicolumn{4}{|l|}{ Age Group } \\
\hline$\bullet<70$ years & $65(54.2 \%)$ & 77 (64.2\%) & $=0.115^{* *}$ \\
\hline$\bullet \geq 70$ years & $55(45.8 \%)$ & $43(35.8 \%)$ & \\
\hline Sex (Male/Female) & $73 / 47$ & $69 / 51$ & $=0.599 * *$ \\
\hline \multicolumn{4}{|l|}{ Educational Status } \\
\hline - Illiterate & 78 (65\%) & 78 (65\%) & $=0.403 * *$ \\
\hline - Basic/Secondary Education & $29(24.2 \%)$ & $23(19.2 \%)$ & \\
\hline - Higher Education & $13(10.8 \%)$ & $19(15.8 \%)$ & \\
\hline \multicolumn{4}{|c|}{ Dementia Diagnostic Scale (Mean \pm SD) } \\
\hline • CASI (literate) & $57.70 \pm 17.7$ & $95.37 \pm 2.5$ & $<0.00 I^{*}$ \\
\hline - CASI (illiterate) & $33.33 \pm 18.7$ & $67.83 \pm 7.6$ & $<0.00 I^{*}$ \\
\hline • MMSE (literate) & $19.81 \pm 4.9$ & $29.45 \pm 0.6$ & $<0.001^{*}$ \\
\hline - MMSE (illiterate) & $12.90 \pm 5.3$ & $22.15 \pm 1.9$ & $<0.00 I^{*}$ \\
\hline
\end{tabular}

Notes: *Independent $t$-test was used to compare the means among groups. $*$ Chi-square analysis was used to compare the frequency among groups. Abbreviations: SD, standard deviation; CASI, Cognitive Abilities Screening Instrument; MMSE, mini-mental state examination. 
DSM-5 diagnostic criteria of neurocognitive disorders, and clinical experience of the staff members in this field. All words and questions in the new questionnaire (DAS) were adjusted to be appropriate for the education, language, and culture of our Arabic population.

The newly constructed scale depends on subjective information from a knowledgeable informant as well as objective assessment of the patient by the clinician. The scale provides quantitative assessment of the following cognitive domains: Orientation (13 marks) to time (present day, month, and year), persons (the attendant person and his relation to him), and place (the client is asked about his orientation to familiar, unfamiliar places and his ability to use transportation means alone). Memory (18 marks) including registration and repetition of 3 unrelated words (pen, field, flag). The client is asked to remember the 3 words at the end of the scale (recent memory), and about his birthday or his home address for remote memory. Attention (23 marks for literate and 22 for illiterate persons), the client is asked to mention days of the week and months of the year forward and backward (for illiterate), and to spell the word boy and flag forward and backward (for literate persons), serial $7 \mathrm{~s}$ and serial $5 \mathrm{~s}$ test. Executive function ( 23 marks 19 for illiterates) including clock face drawing, copying of a geometric shape, and connection between 4 blank circles to form a square. Speech and language assessment (28 marks for literate persons and 18 for illiterates) including category fluency in which the client is asked to mention the maximal number of animal names (birds, fruits) within one minute, assessment of ability of reading, comprehension and writing. Judgment (9 marks), such as the client is asked to mention similarities and differences between grapes and apples, between an orange and a ball. The informant is asked about the patient's ability to do financial transaction and to take proper decisions as before. Social cognition (5 marks) in which the informant is asked about the patient's reckless behavior, whether he speaks to strangers as if he knows them or in a way which hurts the feelings of others, using pornography openly, or speaks about private topics in public. Perceptual motor impairment ( 3 marks): where the informant is asked about the patient's ability to put on and take off his clothes, socks, and shoes, or uses the telephone, or the TV remote as before, or uses a spoon or knife as before, or not.

\section{The Second Stage: Validation of the Scale (DAS) (Face Validity)}

Through this phase, the DAS scale has been reviewed by 11 Professors of Neuropsychiatry as referees from 5 different Egyptian universities and then it is finally adjusted according to their opinions.

\section{The Third Stage: Pilot Study Phase}

DAS scale, was applied to 10 normal healthy subjects with no neurocognitive impairment and 10 patients diagnosed as major NCD according to DSM-5.

\section{The Fourth Stage: Application and Standardization Phase}

In this phase the DAS scale was applied to 120 healthy subjects as a control group, and 120 patients diagnosed to have neurocognitive disorders (NCDs), according to DSM-5 criteria. Mini-mental state examination (MMSE) and cognitive ability screening instrument (CASI) were applied to both patients and controls by a trained clinical psychologist, who was blind to the group status. A few days latter, the DAS scale was applied by another trained clinical psychologist, who was blind to the group status, and scores on MMSE and CASI. Assessment of all participants were done through a face to face interview The DAS total score has a range from 0 to 120 for literate, and from 0 to 105 for illiterate. The administration time takes 15-20 minutes to complete among patients with NCD, while in the control groups it takes $\sim 10-12$ minutes.

\section{Standardization \\ Reliability}

Assessment of the internal consistency of DAS was done through estimation of its Cronbach's alpha and corrected item total correlation coefficient of its sub-items.

\section{Validity}

\section{Contrasted Group Validity}

The scores (mean $\pm \mathrm{SD}$ ) of the patient's and control group on DAS were compared using Student's $t$-test.

\section{Criterion-Related Validity}

By studying the correlation between scores of dementia patients on DAS in relation to their performance on standard tests, such as MMSE as well as CASI.

\section{Diagnostic Validity}

ROC curve was depicted to estimate the sensitivity, specificity, positive predictive value and negative predictive value of the newly constructed scale (DAS). Disease severity diagnostic power of DAS was tested against MMSE severity categories. For illiterates, a score of 21 to 17 for mild, from 16 to 9 for moderate and less than 9 
for severe degrees of dementia. Likewise, for literates, the values of 23 to 19 for mild, 18 to 10 for moderate and less than 10 for severe dementia. ${ }^{21}$

\section{Statistical Analysis}

Data were verified, coded and analyzed using a statistical package for the social sciences (IBM-SPSS version 19). Reliability and internal consistency of the new battery was carried out using Cronbach's alpha coefficient value and corrected item total correlation. Mean $\pm \mathrm{SD}$ and median with range were calculated for (continuous data) scores of the used batteries for both the patients and control group and compared using an independent sample $t$-test for contrasted group validity. Pearson's correlation was done for comparison between the new battery and reference standard tests (MMSE and CASI) (criterion related validity). ROC curve was depicted to investigate the diagnostic performance of different scale scores for the diagnosis of dementia and its severity, analyzed as area under the curve (AUC), and 95\% confidence interval (CI). Validity statistics (sensitivity, specificity, positive and negative predictive value -PPV and NPV-) were calculated. A p-value equal to or less than 0.05 was considered significant.

\section{Results}

There were no statistically significant differences in the basic sociodemographic characteristics between the cases and controls (Table 1). Moreover, demented cases had significantly lower mean scores for CASI and MMSE scales for both illiterate and literate groups compared with the controls (Table 1).

Cronbach's alpha coefficient value of the newly constructed Arabic scale for dementia (DAS) was (0.888). The corrected item total correlation shows that Cronbach's alpha coefficient value minimally decreases if any one of the sub-items was deleted, except for the item of assessing comprehension for illiterate patients.

Pearson's Correlation study between DAS and MMSE shows significant correlation between the total score as well as all corresponding sub-items of the two scales (Table 2). Furthermore, the Correlation study between DAS and CASI shows significant correlation between the total scores of both scales as well as all corresponding subitems of the two scales (Table 3 ).

Table 4 shows that control subjects have significantly higher mean scores than patients diagnosed as having dementia on the total as well as all test sub-items of DAS. The result was significant for literate and illiterate subjects.
Table 2 Shows Criterion-Related Validity of the DAS in Relation to MMSE

\begin{tabular}{|l|l|l|}
\hline DAS & MMSE & $r$ - \\
\hline Orientation to time & Orientation to time & $0.917 * *$ \\
Orientation to Place & Orientation to Place & $0.632^{* *}$ \\
Attention and & Attention and & $0.786 * *$ \\
concentration & concentration & \\
Registration and repetition & Registration and repetition & $0.795 * *$ \\
Short term memory & Short term memory & $0.730^{* *}$ \\
Reading and & Reading and & $0.616^{* *}$ \\
comprehension & comprehension & \\
Writing & Writing & $0.810^{* *}$ \\
Naming & Naming & $0.856 * *$ \\
Executive Function & Drawing & $0.691 * *$ \\
Total DAS & Total MMSE & $0.908^{* *}$ \\
\hline
\end{tabular}

Note: $* * \mathrm{P}=0.01$ or 0.001 .

Abbreviations: DAS, Dementia Arabic Scale; MMSE, mini-mental state examination.

Validity measurements for the different dementia scales as a screening tool are shown in Table 5 and Figure 1. All three scales showed near perfect significant diagnostic power $(\mathrm{AUC}=0.964 .0 .880$ and 0.911 for DAS, MMSE and CASI, respectively). Using different cut-offs for illiterates and literates; scales showed very high validity measures (accuracy $=82 \%$ to $95.5 \%$, sensitivity $=74 \%$ to $100 \%$, specificity $=72 \%$ to $96 \%$, PPV $=78 \%$ to $95.5 \%$ and NPV $=79 \%$ to $100 \%)(\mathrm{p}<0.001)$. This was more evident for literates compared with illiterates. Statistically, DAS was the best measure concerning validity (Table 5).

Table 6 illustrates the validity measures of the DAS score for dementia severity diagnosis. The scale showed

Table 3 Shows Criterion-Related Validity of the DAS in Relation to CASI

\begin{tabular}{|l|l|l|}
\hline DAS & CASI & $\mathbf{r}-$ \\
\hline Orientation to time & Orientation to time & $0.884^{* *}$ \\
Orientation to Place & Orientation to Place & $0.662^{* *}$ \\
Attention and concentration & Attention and concentration & $0.713^{* *}$ \\
Registration and repetition & Registration and repetition & $0.707^{* *}$ \\
Short term memory & Short term memory & $0.887^{* *}$ \\
Long term memory & Long term memory & $0.836 * *$ \\
Reading and comprehension & Reading and comprehension & $0.644^{* *}$ \\
Writing & Writing & $0.686 * *$ \\
Naming & Naming & $0.799 * *$ \\
Executive Function & Drawing & $0.745^{* *}$ \\
Category fluency test & Category fluency test & $0.330^{* *}$ \\
Abstract thinking and judgment & Abstract thinking and judgment & $0.699 * *$ \\
Total DAS & Total CASI & $0.924 * *$ \\
\hline
\end{tabular}

Note: $* * \mathrm{P}=0.01$ or 0.001 .

Abbreviations: DAS, Dementia Arabic Scale; CASI, Cognitive Abilities Screening Instrument. 
Table 4 Contrasted Group Validity

\begin{tabular}{|c|c|c|c|c|c|}
\hline \multirow[t]{2}{*}{ DAS } & $\begin{array}{l}\text { Patient } \\
(N=120)\end{array}$ & $\begin{array}{l}\text { Control } \\
(N=120)\end{array}$ & $\mathbf{T}$ & P. Value & $95 \% \mathrm{Cl}$ \\
\hline & Mean \pm Std & Mean \pm SD & & & \\
\hline I. Orientation & $6.38 \pm 3.12$ & $11.89 \pm 1.33$ & -17.81 & 0.00 & $\{-6.1 \mid 761:-4.89905\}$ \\
\hline 2. Memory & $8.58 \pm 5.40$ & $\mid 4.91 \pm 2.91$ & -11.311 & 0.000 & $\{-7.436:-5.22855\}$ \\
\hline a) Registration and repetition: & $2.5667 \pm .9050 \mathrm{I}$ & $3.0000 \pm .00000$ & -5.245 & 0.000 & $-0.59609:-0.27058$ \\
\hline b) Long term memory & $3.2083 \pm 2.11396$ & $4.3000 \pm 1.40587$ & -4.710 & 0.000 & $-1.54822:-0.63511$ \\
\hline c) Short term memory: & $2.8000 \pm 3.79872$ & $7.6083 \pm 2.16269$ & -12.050 & 0.000 & $-5.59443:-4.02224$ \\
\hline 3. Attention and Concentration (total) & $9.2250 \pm 6.88130$ & $14.5333 \pm 4.75789$ & -6.951 & 0.000 & $-6.81282:-3.80384$ \\
\hline a) Attention and concentration DAS (literate) & $15.8095 \pm 6.24398$ & $20.357 I \pm 2.34595$ & -4.418 & 0.000 & $-6.59507:-2.50016$ \\
\hline b) Attention and concentration DAS (illiterate) & $5.68 \pm 4.01$ & $11.42 \pm 1.91$ & 11.432 & 0.000 & $\{-6.736 \mid 0:-4.75108\}$ \\
\hline 4. Executive Function DAS & $4.9500 \pm 6.56941$ & $|2.3500 \pm 6.0802|$ & -9.056 & 0.000 & $-9.00975:-5.79025$ \\
\hline a) Executive Function DAS (illiterate) & $1.9487 \pm 2.51178$ & $8.2692 \pm 2.77125$ & -14.925 & 0.000 & $\{-7.157 \mid 1:-5.48391\}$ \\
\hline b) Executive Function DAS (literate) & $10.2143 \pm 8.15262$ & $19.7619 \pm 2.38705$ & -7.284 & 0.000 & $-12.15520:-6.94004$ \\
\hline 5. Abstract thinking and judgment & $4.0333 \pm 2.80436$ & $7.2000 \pm 1.28076$ & -11.252 & 0.000 & $-3.72109:-2.61224$ \\
\hline 6. Speech and articulation & $4.5250 \pm 1.69012$ & $6.0000 \pm .00000$ & -9.560 & 0.000 & $-1.77894:-1.17106$ \\
\hline a) Category fluency test DAS & $0.2083 \pm .70884$ & $1.9500 \pm .93350$ & -16.277 & 0.000 & $-1.95245:-1.53088$ \\
\hline b) Naming: & $2.7750 \pm .71552$ & $3.0000 \pm .00000$ & -3.445 & 0.001 & $-0.35368:-0.09632$ \\
\hline c) Reading and comprehension & $5.6667 \pm 2.66737$ & $6.7500 \pm 2.39485$ & -3.311 & 0.001 & $-1.72799:-0.43868$ \\
\hline $\begin{array}{l}\text { 1) For illiterate patient: ask him to catch the red pencil and give it } \\
\text { to the doctor? (illiterate) }\end{array}$ & $4.7436 \pm 1.11000$ & $5.0000 \pm .00000$ & -2.040 & 0.043 & $-0.50470:-0.00813$ \\
\hline $\begin{array}{l}\text { 2) For literate patient: read the sentence and do the instruction? } \\
\text { (literate) }\end{array}$ & $7.3810 \pm 3.70203$ & $10.000 \pm 0.0000$ & -4.585 & 0.000 & $-3.75542:-1.48268$ \\
\hline d) Writing: & $2.5714 \pm 2.33889$ & $5.0000 \pm .00000$ & -6.729 & 0.000 & $\{-3.14651:-1.71063-\}$ \\
\hline 7. Impairments of social cognition: & $4.0917 \pm 1.02076$ & $5.0000 \pm .00000$ & -9.748 & 0.000 & $-1.09190:-0.72477$ \\
\hline 8. Perceptual motor impairment & $1.5833 \pm 1.31943$ & $3.0000 \pm .00000$ & -11.762 & 0.000 & $-1.65394:-1.17939$ \\
\hline Total DAS (illiterate) $N=78$ & $41.28 \pm 16.76$ & $75.41 \pm 6.79$ & 16.67 & 0.000 & $\{-38.17:-30.083\}$ \\
\hline Total DAS (literate) $N=42$ & $73.98 \pm 26.38$ & || $2.2| \pm 4.9|$ & 9.234 & 0.000 & $\{-46.47578:-30.0004 I\}$ \\
\hline
\end{tabular}

Abbreviations: DAS, Dementia Arabic Scale; SD, standard deviation; C.I., confidence interval.

Table 5 Diagnostic Performance of Different Scales for Prediction of Dementia, Analyzed as Area Under the Curve (95\% Cl)

\begin{tabular}{|c|c|c|c|c|c|c|}
\hline & \multicolumn{2}{|c|}{ Total DAS } & \multicolumn{2}{|c|}{ Total MMSE } & \multicolumn{2}{|c|}{ Total CASI } \\
\hline $\operatorname{AUC}(95 \% \mathrm{Cl})$ & \multicolumn{2}{|c|}{$0.964(0.932-0.995)^{*}$} & \multicolumn{2}{|c|}{$0.880(0.838-0.927)$} & \multicolumn{2}{|c|}{$0.911(0.875-0.948)$} \\
\hline \multirow[t]{2}{*}{ P-value** } & \multicolumn{2}{|c|}{$<0.001$} & \multicolumn{2}{|c|}{$<0.001$} & \multicolumn{2}{|c|}{$<0.001$} \\
\hline & Literate & Illiterate & Literate & Illiterate & Literate & Illiterate \\
\hline Cutoff & 95 & 68 & 23 & 21 & 80 & 50 \\
\hline Accuracy & $92 \%$ & $91.5 \%$ & $86 \%$ & $82 \%$ & $95.5 \%$ & $89.5 \%$ \\
\hline Sensitivity \% & $100 \%$ & $87 \%$ & $100 \%$ & $74 \%$ & $100 \%$ & $100 \%$ \\
\hline Specificity \% & $84 \%$ & $96 \%$ & $72 \%$ & $90 \%$ & $91 \%$ & $79 \%$ \\
\hline PPV \% & $86 \%$ & $95.5 \%$ & $78 \%$ & $88 \%$ & $92 \%$ & $83 \%$ \\
\hline NPV \% & $100 \%$ & $88 \%$ & $100 \%$ & $79 \%$ & $100 \%$ & $100 \%$ \\
\hline
\end{tabular}

Notes: Sensitivity (true positives/all diseased); specificity (true negatives/all non-diseased); PPV (true positives/all test positives); NPV (true negatives/all test negatives). $* \mathrm{SE}=$ standard error $+\mathrm{Cl}=$ confidence interval. $* *$ Null hypothesis: true area $=0.5$.

Abbreviations: AUC, area under the curve; DAS, Dementia Arabic Scale; MMSE, mini-mental state examination; CASI, Cognitive Abilities Screening Instrument. 


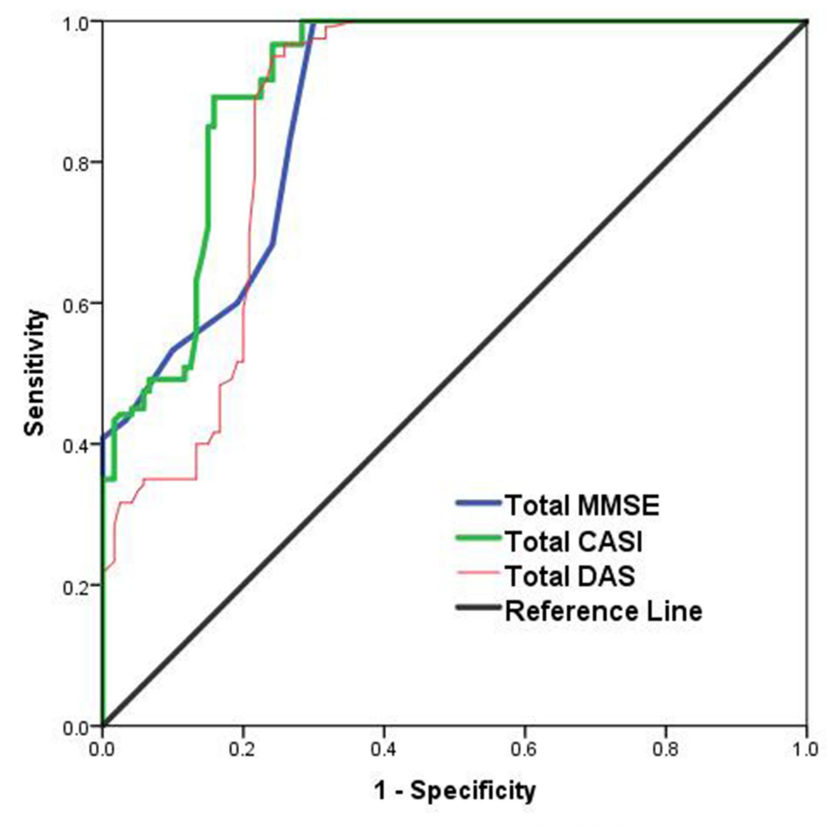

Diagonal segments are produced by ties.

Figure I ROC curve for different scales for prediction of dementia.

near perfect significant diagnostic power $(\mathrm{AUC}=0.977$, 0.987 , and 0.981 for mild, moderate, and severe dementia, respectively). The best identified cut-off values for literates were 95, 62 and 35 for mild, moderate, and severe cases, respectively. Likewise, the best identified cut-off values for illiterates were 68, 57 and 35 for mild, moderate, and severe cases, respectively. Using these cut-off values; DAS scale showed very high validity measures for both groups (accuracy $=90.5 \%$ to $97 \%$, sensitivity $=81 \%$ to $100 \%$, specificity $=90 \%$ to $100 \%$, $\mathrm{PPV}=90.5 \%$ to $100 \%$ and $\mathrm{NPV}=84 \%$ to $100 \%$ ) $(\mathrm{p}<0.001)$.

\section{Discussion}

The true prevalence of neurological disorders in most developing countries is still underestimated. One of the major reasons for this is the current lack of a suitable tool for its proper measurement. ${ }^{25}$ To be suitable, the tool must be culturally and linguistically suited for the designed studied population. So, the existing instruments may underestimate the true burden. ${ }^{26}$

A screening instrument must be feasible, reliable and valid. It must be accepted by the community, easily applied by a nonmedical trainee, and brief. It must be sensitive enough to pick up most suspected persons with NCD for subsequent detailed diagnosis, and at the same time it should be specific enough so as not to overwhelm specialists. An excessive number of false positives could make the survey logistically impossible to perform. This latter point is the greatest challenge for epidemiologists in resource-poor settings. ${ }^{27}$

In the current study the percentage of illiteracy $(65 \%)$ is much higher than literacy (35\%). This might indicate that illiteracy could be a risk factor for dementia. In this context, Nitrini et al (2009) performed meta-analysis of dementia studies in Latin America and similarly, they found that the prevalence of dementia among illiterates was two folds that among literates. ${ }^{28}$

In addition to the significant correlation between total score of DAS and MMSE, the newly constructed scale (DAS) has more cognitive domains which are not matched in MMSE as Judgment, Orientation to person, Long term memory, Category fluency test, Impairment of social cognition, Perceptual motor impairment and subjective testing of Speech and Language.

Table 6 Diagnostic Performance of DAS Scales for Prediction of Dementia Severity, Analyzed as Area Under the Curve (95\% Cl)

\begin{tabular}{|c|c|c|c|c|c|c|}
\hline & \multicolumn{2}{|c|}{ Mild } & \multicolumn{2}{|c|}{ Moderate } & \multicolumn{2}{|c|}{ Severe } \\
\hline AUC $(95 \% \mathrm{Cl})$ & \multicolumn{2}{|c|}{$0.977(0.958-0.995)^{*}$} & \multicolumn{2}{|c|}{$0.987(0.963-1.000)$} & \multicolumn{2}{|c|}{$0.98 \mid(0.964-0.999)$} \\
\hline \multirow[t]{2}{*}{ P-value** } & \multicolumn{2}{|c|}{$<0.001$} & \multicolumn{2}{|c|}{$<0.001$} & \multicolumn{2}{|c|}{$<0.001$} \\
\hline & Literate & Illiterate & Literate & Illiterate & Literate & Illiterate \\
\hline Cutoff & 95 & 68 & 62 & 57 & 35 & 35 \\
\hline Accuracy & $97 \%$ & $90.5 \%$ & $93.5 \%$ & $92.5 \%$ & $97.5 \%$ & $95 \%$ \\
\hline Sensitivity \% & $100 \%$ & $81 \%$ & $97 \%$ & $93 \%$ & $95 \%$ & $94 \%$ \\
\hline Specificity \% & $94 \%$ & $100 \%$ & $90 \%$ & $92 \%$ & $100 \%$ & $96 \%$ \\
\hline PPV \% & $94.5 \%$ & $100 \%$ & $90.5 \%$ & $92 \%$ & $100 \%$ & $96 \%$ \\
\hline NPV \% & $100 \%$ & $84 \%$ & $96.5 \%$ & $93 \%$ & $95.5 \%$ & $94 \%$ \\
\hline
\end{tabular}

Notes: Sensitivity (true positives/all diseased); specificity (true negatives/all non-diseased); PPV (true positives/all test positives); NPV (true negatives/all test negatives). $* \mathrm{SE}=$ standard error $+\mathrm{Cl}=$ confidence interval. $* *$ Null hypothesis: true area $=0.5$.

Abbreviation: AUC, area under the curve. 
In this regard, the newly constructed DAS shows higher correlation with the Arabic version of MMSE, than the Arabic version of Cognitive Subscale of the Alzheimer's Disease Assessment Scale (A-ADAS-Cog) ${ }^{16}$ with Arabic MMSE. It was also higher than the correlation between cognitive subscale of Alzheimer's Disease Assessment Scale (A-ADAS-Cog) and clinical dementia rating scale (CDR) by Sum of Boxes (CDR-SB; $r=0.87$ ), or global CDR score (CDR-Global; $r=0.74)$.

In the present study, there is significant correlation between total score of DAS and CASI. Moreover it is worth noting that there are items in DAS that are neither matched by CASI nor MMSE. These include: (Impairment of social cognition, Perceptual motor impairment, and subjective Speech and Language impairment). This might reflect the significance of the newly constructed scale in picking up subjects having impairment of these cognitive domains, implying the early diagnosis of dementia.

The DAS scale showed high validity measurements for both literacy and illiteracy among Arabic-speaking subjects. The sensitivity of DAS was higher than the Arabic version of ADAS-Cog (84\% at cut off 10$).{ }^{16}$ More than half of patients with neurocognitive disorders (NCD) were categorized as Alzheimer's disease in the present study, thus DAS is suitable as a screening tool for Alzheimer's disease and other dementias among the Arabic-speaking literate and illiterate population.

Furthermore, Chaaya et al (2015) evaluated the validation of the Rowland Universal Dementia Assessment Scale in Arabic language (A-RUDAS) to screen for mild and moderate dementia. The scale exhibited good sensitivity $(83 \%)$ and specificity (85\%) with an AUC of $83.95 \%$, while the ROC analysis of DAS demonstrated that the clinical validity was excellent (AUC $=0.964$ (96.4\%)). This indicates the higher ability of DAS in discriminating cases of dementia from negative cases in clinical practice among the Arabic-speaking population. ${ }^{13}$

The strength of this study is that the constructed DAS is carried out in the native language (Arabic) to be used in screening and diagnosis of dementia among the Arabicspeaking population. However, its limitation is that although the scale was constructed for Arabic- speaking countries, participants were included from only one country. Thus further studies with representation from different Arab countries might be required to control for the effects of subcultures in the different Arab countries.

\section{Conclusions}

The newly constructed DAS scale, which was constructed in Arabic to be suitable for Arabic-speaking populations, demonstrated a high level of accuracy in diagnosis for dementia, and it can be used for dementia diagnosis instead of the previously translated scales. Furthermore, it can be suitable for both literate and illiterate subjects.

\section{Abbreviations}

DAS, Dementia Arabic Scale; MMSE, mini-mental state examination; CASI, Cognitive Abilities Screening Instruments; NCD: neurocognitive disorders; RUDAS, Rowland Universal Dementia Assessment Scale; AQ, Alzheimer's Questionnaire; AD, Alzheimer's disease; EDQ, Early Dementia Questionnaire; MoCA, Montreal Cognitive Assessment; ADAS-Cog, Alzheimer's Disease Assessment Scale-Cognitive Subscale; MCI, mild cognitive impairment.

\section{Data Sharing Statement}

Data and materials supporting the results of this article are available from the corresponding author on reasonable request.

\section{Ethical Approval and Informed Consent}

Ethical approval for this study was provided by the Ethics Committee of Assiut University. This study was conducted in accordance with the Declaration of Helsinki. Written informed consent was obtained from all participants or their authorized surrogates.

\section{Acknowledgments}

We wish to thank the study participants for their valuable contribution.

\section{Author Contributions}

All authors made substantial contributions to conception and design, acquisition of data, or analysis and interpretation of data; took part in drafting the article or revising it critically for important intellectual content; agreed to submit to the current journal; gave final approval of the version to be published; and agree to be accountable for all aspects of the work. 


\section{Disclosure}

The authors declared no potential conflicts of interest with respect to the research, authorship, and/or publication of this article.

\section{References}

1. Hugo J, Ganguli M. Dementia and cognitive impairment: epidemiology, diagnosis, and treatment. Clin Geriatr Med. 2014;30 (3):421-442. doi:10.1016/j.cger.2014.04.001

2. World Helath Organization. Dementia: a public health priority. World health organization. Available from: https://www.who.int/mental health/publications/dementia_report_2012/en/. Accessed 2012.

3. El Tallawy HN, Farghly WM, Shehata GA, et al. Prevalence of dementia in Al Kharga District, New Valley Governorate, Egypt. Neuroepidemiology. 2012;38(3):130-137. doi:10.1159/000335655

4. El Tallawy HN, Farghly WM, Badry R, et al. Prevalence of dementia in Al-Quseir city, Red Sea Governorate, Egypt. Clin Interv Aging. 2014;9:9-14. doi:10.2147/CIA.S48325

5. El Tallawy HN, Farghaly WM, Rageh TA. Door-to-door survey of major neurological disorders (project) in Al Quseir City, Red Sea Governorate, Egypt. Neuropsychiatr Dis Treat. 2013;9:767-771. doi:10.2147/NDT.S36956

6. Khedr E, Fawi G, Abbas MA, et al. Prevalence of mild cognitive impairment and dementia among the elderly population of Qena Governorate, Upper Egypt: a community-based study. J Alzheimers Dis. 2015;45(1):117-126. doi:10.3233/JAD-142655

7. Abou-Mrada F, Chelunec G, Zamrinic E, Tarabey L, Hayek M, Fadel P. Screening for dementia in Arabic: normative data from an elderly Lebanese sample. Clin Neuropsychol. 2017;31(sup1):1-19. doi:10.1080/13854046.2017.1288270

8. Folstein MF, Folstein SE, McHugh PR. 'MiniMental State': a practical method for grading the cognitive state of patients for the clinician. J Psychiatr Res. 1975;12(3):189-198. doi:10.1016/00223956(75)90026-6

9. Brayne C, Calloway P. The association of education and socioeconomic status with the mini mental state examination and the clinical diagnosis of dementia in elderly people. Age Ageing. 1990;19 (2):91-96. doi:10.1093/ageing/19.2.91

10. Fratiglioni L, Jorm AF, Grut M, et al. Predicting dementia from the mini-mental state examination in an elderly population: the role of education. J Clin Epidemiol. 1993;46(3):281-287. doi:10.1016/08954356(93)90076-D

11. Mitchell AJ. A meta-analysis of the accuracy of the mini-mental state examination in the detection of dementia and mild cognitive impairment. J Psychiatr Res. 2009;43(4):411-431. doi:10.1016/j. jpsychires.2008.04.014

12. Stanczak DE, Stanczak EM, Awadalla AW. Development and initial validation of an Arabic version of the expanded trail making test: implications for cross-cultural assessment. Arch Clin Neuropsychol. 2001;16(2):141-149.

13. Chaaya M, Phung TK, El Asmar K, et al. Validation of the Arabic Rowland Universal dementia assessment scale (A-RUDAS) in elderly with mild and moderate dementia. Aging Ment Health. 2016;20(8):880-887. doi:10.1080/13607863.2015.1043620

14. Elie Karam G, Khandakji MN, Sahakian NS, Dandan JC, Karam EG. Validation into Arabic versions of Dementia rating scales, Dementia caregivers scales, and Dementia research instruments. Alzheimers Dement (Amst). 2018;10(1):796-801. doi:10.1016/j.dadm.2018.06.003
15. Malek-Ahmadi M, Davis K, Belden C, et al. Validation and diagnostic accuracy of the Alzheimer's questionnaire. Age Ageing. 2012;41 (3):396-399. doi:10.1093/ageing/afs008

16. Ben Jemaa S, Romdhane NA, Bahri-Mrabet A, Jendli A, Le Gall D, Bellaj D. An Arabic Version of the cognitive subscale of the Alzheimer's Disease Assessment Scale (ADAS-Cog): reliability, validity, and normative data. J Alzheimers Dis. 2017;60(1):11-21. doi:10.3233/JAD-170222

17. Qassem T, Khater MS, Emara T, et al. Validation of the EgyptianArabic Version of the Addenbrooke's Cognitive Examination III (ACE-III) in diagnosing dementia. Dement Geriatr Cogn Disord. 2020;49(2):179-184. doi:10.1159/000507758

18. Al Salman A, Wahass S, Rahman Altahan A, et al. Validation of an Arabic version of the Addenbrooke's Cognitive ExaminationRevised. Brain Impairment. 2011;12(Suppl):24.

19. Rahman TTA, El Gaafary MM. Montreal cognitive assessment arabic version: reliability and validity prevalence of mild cognitive impairment among elderly attending geriatric clubs in Cairo. Geriatr Gerontol Int. 2009;9(1):54-61. doi:10.1111/j.1447-0594.2008.00509.x

20. American Psychiatric Association. Diagnostic and Statistical Manual of Mental Disorders. 5th ed. Washington, DC: American Psychiatric Association; 2013.

21. Farrag A, Farwiz HM, Khedr EH, Mahfouz RM, Omran SM. Prevalence of Alzheimer's disease and other dementing disorders: assiut-Upper Egypt study. Dement Geriatr Cogn Disord. 1998;9 (6):323-328. doi:10.1159/000017084

22. ElKholy N, Tawfik HM, Ebeid S, Hamza SA, Madkor OR. Defining cut-off scores for MMSE in an educated and illiterate arabic speaking egyptian elderly population. EJGG. 2018;6(1):31-33.

23. Teng EL, Hasegawa K, Homma A, et al. The Cognitive Abilities Screening Instrument (CASI): a practical test for cross-cultural epidemiological studies of dementia. Int Psychogeriatr. 1994;6 (1):45-56. doi:10.1017/S1041610294001602

24. Lin K, Wang P, Liu C, Chen W, Lee Y, Liu H. Cutoff scores of the cognitive abilities screening instrument, chinese version in screening of Dementia. Dement Geriatr Cogn Disord. 2002;14(4):176-182. doi:10.1159/000066024

25. World Health Organization. Neurological disorders: public health challenges. World Health Organization. Available from: https:// www.who.int/mental_health/publications/neurological_disorders_ph_ challenges/en/. Accessed 2006.

26. Lopez AD, Mathers CD, Ezzati M, Jamison DT, Murray C. Global and regional burden of disease and risk factors,: systematic analysis of population health data. Lancet. 2006;367(9524):1747-1757. doi:10.1016/S0140-6736(06)68770-9

27. Meneghini F, Rocca WA, Anderson DW, et al. Validating screening instruments for neuroepidemiologic surveys: experience in Sicily. Sicilian Neuro-Epidemiologic Study (SNES) Group. $J$ Clin Epidemiol. 1992;45(4):19-31. doi:10.1016/0895-4356(92)90033-J

28. Nitrin R, Cassio MC, Albala C, et al. Prevalence of dementia in Latin America: a collaborative study of population-based cohorts. Int Psychogeriatr. 2009;21(4):622-630. doi:10.1017/S104161020 9009430 


\section{Publish your work in this journal}

Neuropsychiatric Disease and Treatment is an international, peerreviewed journal of clinical therapeutics and pharmacology focusing on concise rapid reporting of clinical or pre-clinical studies on a range of neuropsychiatric and neurological disorders. This journal is indexed on PubMed Central, the 'PsycINFO' database and CAS, and is the official journal of The International Neuropsychiatric Association (INA). The manuscript management system is completely online and includes a very quick and fair peer-review system, which is all easy to use. Visit http://www.dovepress.com/testimonials.php to read real quotes from published authors.

Submit your manuscript here: https://www.dovepress.com/neuropsychiatric-disease-and-treatment-journal 